\title{
RECUPERAÇÃO DE ATRIBUTOS FÍSICOS DE UM ARGISSOLO EM FUNÇÃO DO SEU REVOLVIMENTO E DO TEMPO DE SEMEADURA DIRETA ${ }^{(1)}$
}

\author{
Alaerto Luiz Marcolan ${ }^{(2)}$, Ibanor Anghinoni ${ }^{(3)}$, Thiago Isquierdo \\ Fraga $^{(4)}$ \& João Guilherme Dal Belo Leite ${ }^{(5)}$
}

\begin{abstract}
RESUMO
A melhoria da qualidade estrutural do solo pelo uso continuado do sistema semeadura direta ocorre junto com o processo de sua (re)acidificação. Em algumas circunstâncias, ocorre também compactação superficial devido ao tráfego de máquinas, que necessita ser corrigida pela mobilização do solo. Assim, em experimento conduzido há 12 anos sob diferentes sistemas de manejo do solo, avaliou-se o tempo necessário para o solo readquirir os atributos físicos iniciais, alterados no processo de revolvimento do solo, por ocasião da reaplicação de calcário. O experimento foi realizado na Estação Experimental Agronômica da UFRGS, em Eldorado do Sul - RS, em um Argissolo Vermelho distrófico típico. Os sistemas de manejo avaliados foram: (a) preparo convencional durante 12 anos, (b) sistema semeadura direta com revolvimento do solo para incorporar calcário a cada quatro anos, (c) sistema semeadura direta durante oito anos e (d) sistema semeadura direta durante 12 anos. Determinaram-se, imediatamente antes e 6, 12, 24, 36 e 48 meses depois da terceira reaplicação de calcário, a densidade, a porosidade total, a macroporosidade, a microporosidade, a estabilidade de agregados e o teor de $C$ orgânico em três camadas $(0,0-2,5 ; 2,5-7,5$ e 7,5-15,0 cm) de solo. O revolvimento do solo para incorporação do calcário no sistema semeadura direta de quatro anos propiciou condições mais favoráveis de densidade e porosidade do solo, mas diminuiu a estabilidade de agregados. Houve necessidade de um período de quatro anos de cultivo do solo no sistema semeadura direta para o retorno da estabilidade de agregados à condição original. Os atributos físicos do solo foram mais uniformes no perfil no preparo convencional, porém com menor estabilidade de agregados na camada superficial, que foi relacionada ao teor de $\mathrm{C}$ orgânico.
\end{abstract}

Termos de indexação: mobilização do solo, agregação, densidade, porosidade.

\footnotetext{
(1) Recebido para publicação em setembro de 2005 e aprovado em fevereiro de 2007.

(2) Pesquisador Embrapa Rondônia. BR $364 \mathrm{Km} \mathrm{5,5,} \mathrm{Caixa} \mathrm{Postal} \mathrm{406,} \mathrm{CEP} \mathrm{78900-970} \mathrm{Porto} \mathrm{Velho} \mathrm{(RO).} \mathrm{E-mail:}$ marcolan@cpafro.embrapa.br

(3) Professor do Departamento de Solos, Universidade Federal do Rio Grande do Sul - UFRGS. Av. Bento Gonçalves 7712 , CEP 91540-000 Porto Alegre (RS). Bolsista do CNPq. E-mail: ibanghi@ufrgs.br

(4) Bolsista da FAPERGS.

(5) Bolsista do PIBIC CNPq/UFRGS.
} 


\title{
SUMMARY: RECOVERY OF PHYSICAL ATTRIBUTES OF AN ULTISOL AS AFFECTED BY SOIL TILLAGEAND SOWING TIME IN NO-TILLAGE
}

\begin{abstract}
The improvement in the structural soil quality under continuous no-tillage occurs concomitantly to soil (re)acidification. Surface compaction can sometimes occur, owing to machinery traffic, which has to be corrected by soil tilling. In a 12-year experiment under different soil management systems we evaluated the time it takes to recover the initial soil physical attributes that are affected by soil tillage by the occasion of lime reapplication. The experiment was set up on a Rhodic Paleudult (Ultisol) at the Agronomical Experimental Station-UFRGS, in Eldorado do Sul, state of Rio Grande do Sul, Brazil, for 12 years under conventional and 4, 8 and 12 years under no-tillage systems. The soil physical attributes (bulk density, porosity and aggregate stability) and organic carbon content were evaluated in three (0-2.5, 2.5-7.5 and 7.5-15.0 cm) soil layers, just before and 6, 12, 24, 36 and 48 months after the third lime application. By tilling the soil at lime incorporation after four years of notillage, bulk density and porosity improved, but the aggregate stability decreased. Four years under no-tillage were necessary to recover the original aggregate stability condition. Soil physical attributes were more uniform in conventional tillage, but the aggregate stability in the surface layer was lower, and was related to the organic carbon content.
\end{abstract}

Index terms: soil tillage, aggregation, bulk density, porosity.

\section{INTRODUÇÃO}

A despeito da prática de incorporar o calcário ao solo, em decorrência da sua baixa solubilidade, vigente até meados da década passada, os técnicos e produtores persistiam com a aplicação superficial desse corretivo com o intuito de preservar as características físicas favoráveis obtidas no sistema semeadura direta, especialmente a agregação e a infiltração de água no solo (Carpenedo \& Mielniczuk, 1990; Da Ros et al., 1997; Castro Filho et al., 1998).

Apesar de a pesquisa sobre essa temática ter se iniciado nessa mesma época, os resultados a respeito da viabilidade dessa prática surgiram mais tarde. Assim, verificou-se que a aplicação superficial de calcário no sistema semeadura direta era eficiente na correção da acidez em profundidade e na produtividade das culturas (Mielniczuk et al., 1995; Oliveira \& Pavan, 1996; Sá, 1996; Pöttker \& Ben, 1998; Caires et al., 2000; Rheinheimer et al., 2000; Petrere \& Anghinoni, 2001; Amaral et al., 2004).

Entretanto, apesar das mudanças positivas nas características físicas e químicas do solo propiciadas pelo sistema semeadura direta, o cultivo continuado pode levar à consolidação natural do solo, advinda da ausência de preparo, ou à sua compactação superficial, devido à pressão exercida pelo tráfego de máquinas durante as operações necessárias ao cultivo. Há, também, situações em que a aplicação superficial de calcário resulta em $\mathrm{pH}$ muito elevado $(>7,0)$ na superfície, como vem ocorrendo na região do Planalto do Rio Grande do Sul. Um eventual revolvimento do solo, nessa situação, pode melhorar o espaço poroso, ao mesmo tempo em que mistura o calcário na camada arável do solo $(0-20 \mathrm{~cm})$. A conseqüente redução da densidade, do aumento da macroporosidade e da incorporação do calcário e do material orgânico acumulado na superfície disponibilizaria nutrientes para as culturas e proporcionaria um ambiente mais propício ao desenvolvimento radicular e crescimento vegetal.

O conhecimento das conseqüências de um revolvimento eventual do solo no sistema semeadura direta torna-se oportuno nesse momento. Questionase então se, realmente, o revolvimento do solo a períodos de quatro a seis anos não poderia ser utilizado sem prejuízo da sua qualidade estrutural. Pode-se supor, ao menos em princípio, que os efeitos não seriam tão intensos como os verificados pelas freqüentes mobilizações do solo cultivado no preparo convencional.

São raros, ainda, os estudos comparando os efeitos da aplicação superficial e da incorporação de calcário em áreas manejadas no sistema semeadura direta. Dessa forma, utilizou-se de um experimento conduzido há 12 anos sob diferentes sistemas de manejo do solo, com o objetivo de avaliar o tempo necessário para o solo readquirir os atributos físicos iniciais, alterados no processo de revolvimento do solo, por ocasião da reaplicação de calcário.

\section{MATERIAL E MÉTODOS}

O experimento foi instalado em 1988, na Estação Experimental Agronômica da Universidade Federal do Rio Grande do Sul, no município de Eldorado do Sul (RS), em Argissolo Vermelho distrófico típico (Embrapa, 1999), de textura franco-argiloarenosa.

Em maio de 1988, foram aplicados 3,4 $\mathrm{Mg} \mathrm{ha}^{-1} \mathrm{de}$ calcário dolomítico (PRNT 100\%) sobre uma área com pastagem nativa, por 15 anos, para elevar o $\mathrm{pH}$ a 6,0, incorporando-o por meio de uma aração e duas 
gradagens; em julho, aveia-preta (Avena strigosa S.) foi semeada, objetivando a produção de biomassa para cobertura do solo. Em outubro, antes de estabelecer a cultura do milho (Zea mays L.), foram aplicados os tratamentos de preparo convencional (uma aração até $17 \mathrm{~cm}$ de profundidade e duas gradagens) e sem preparo (semeadura direta). Aárea experimental foi cultivada por quatro anos com milho, no verão, e aveia-preta, no inverno. As adubações de $\mathrm{N}$, de $\mathrm{P}$ e de $\mathrm{K}$ para o milho e de $\mathrm{N}$ para a aveia-preta foram efetuadas com base na análise do solo, conforme a Comissão de Fertilidade do Solo (Siqueira et al., 1987; CFS RS/SC, 1995).

Em setembro de 1992 , efetuou-se a primeira reaplicação de calcário dolomítico, na dose de 3,7 $\mathrm{Mg} \mathrm{ha}^{-1}$ (PRNT 100\%), com o objetivo de elevar o pH a 6,0, tendo sido o solo das parcelas revolvidos, para incorporar o calcário, ou não, de modo que fossem obtidos os seguintes tratamentos: (a) preparo convencional contínuo por quatro anos, (b) sistema semeadura direta com revolvimento do solo no quarto ano, para incorporar o calcário, (c) sistema semeadura direta precedida por quatro anos de preparo convencional e (d) sistema semeadura direta contínua por quatro anos. O experimento foi então conduzido, por mais quatro anos, com revolvimento do solo somente nas subparcelas de preparo convencional contínuo. Em outubro de 1996, realizou-se a segunda reaplicação de calcário dolomítico, na dose de 2,5 Mg ha-1 (PRNT 100\%), e, em outubro de 2000, a terceira, na dose de 4,1 $\mathrm{Mg} \mathrm{ha}^{-1}$ (PRNT 100\%), seguindo os mesmos procedimentos adotados nas reaplicações anteriores. Assim, no ano 2000, o experimento apresentava os seguintes tratamentos: (a) preparo convencional durante 12 anos, (b) sistema semeadura direta durante 12 anos com revolvimento do solo a cada quatro anos, para incorporar o calcário, (c) sistema semeadura direta durante oito anos, antecedido por quatro anos de preparo convencional, e (d) sistema semeadura direta durante 12 anos. Esses tratamentos estavam distribuídos de forma casualizada em três blocos.

A partir de 1997, introduziu-se a ervilhaca comum (Vicia sativa) à aveia-preta. Nos anos de 2000 a 2004, em que se realizaram as avaliações, cultivou-se o híbrido de milho Pioneer 3069. A adubação foi efetuada com base na análise do solo das parcelas de preparo convencional contínuo, conforme a CFS RS/ $\mathrm{SC}$, (1995). O espaçamento dentro da linha foi de $0,2 \mathrm{~m}$ e, entre as linhas, de 1,0 m. A semeadura foi feita com matraca, e a população, após desbaste, era de aproximadamente 50.000 plantas ha-1. Após a colheita para avaliação do rendimento de grãos, as plantas de milho foram manejadas com rolo-faca, para cultivo de aveia-preta + ervilhaca comum (espaçamento entre linhas de $17 \mathrm{~cm}$ e sulco para semeadura de aproximadamente $2 \mathrm{~cm}$ de profundidade). Depois da avaliação do rendimento de matéria seca da mistura forrageira, as plantas foram dessecadas com glifosato na dose de $3 \mathrm{~L} \mathrm{ha}^{-1} \mathrm{e}$ manejadas com rolo-faca.
O solo foi amostrado em seis ocasiões, sendo a primeira em setembro de 2000, antecedendo a aplicação de calcário, 12 anos após o início do experimento. A segunda amostragem foi efetuada em abril de 2001; a terceira, a quarta, a quinta e a sexta, respectivamente em setembro de 2001, 2002, 2003 e 2004, correspondendo a $6,12,24,36$ e 48 meses após a reaplicação do calcário. As amostras de solo foram coletadas com pá-de-corte e com anéis volumétricos, em três locais nas entrelinhas do milho de cada parcela, nas profundidades de 0-2,5; 2,5-7,5 e 7,5-15,0 cm. Os atributos avaliados foram: C orgânico total, pelo método de Walkley \& Black, conforme Tedesco et al. (1995); densidade de solo, segundo Blake \& Hartge (1986); macroporosidade, microporosidade e porosidade total, de acordo com Danielson \& Sutherland (1986), usando-se funil com placa porosa de vidro, tensão e sucção matricial de $6 \mathrm{kPa}$; e estabilidade de agregados, com base no método de Kemper \& Chepil (1965), utilizando peneiragem úmida e seca em agregados menores que $9,51 \mathrm{~mm}$ e um conjunto de peneiras, com malhas de 4,$76 ; 2,00 ; 1,00 ; 0,50$ e $0,25 \mathrm{~mm}$.

$\mathrm{O}$ índice de estabilidade dos agregados foi obtido pela razão DMPu/DMPs (diâmetro médio ponderado obtido pela agitação úmida, dividido pelo obtido por agitação a seco). Informações mais detalhadas são encontradas em Marcolan (2002).

Realizou-se a análise de variância dos resultados, considerando-se o delineamento experimental de blocos ao acaso, utilizando-se o teste de Tukey $(\mathrm{P}<0,05)$ para comparação entre médias, de acordo com o modelo (1), com a inclusão da restrição aos fatores profundidade e época de avaliação:

$$
\begin{aligned}
& \mathrm{Y} i j k=\mu+\mathrm{Bi}+\mathrm{Ej}+\text { erro a }(\mathrm{ij})+\mathrm{Pk}+ \\
& \text { erro b (ik) }+ \text { EPjk }+ \text { erro c (ijk) }
\end{aligned}
$$

em que $\mathrm{B}=$ blocos $(\mathrm{i}=1,2,3) ; \mathrm{E}=$ época de avaliação $(\mathrm{j}=1,2,3,4,5,6)$; e $\mathrm{P}=$ profundidade do solo $(\mathrm{k}=1,2,3)$.

\section{RESULTADOS E DISCUSSÃO}

No preparo convencional contínuo por 12 anos, a densidade do solo, a porosidade total e a macroporosidade não foram modificadas nas diferentes épocas de avaliação (Figuras 1a, 2a e 3a). Já a microporosidade, embora não se esperasse, devido ao revolvimento anual do solo, apresentou diferença entre as épocas de avaliação (Figura 4a).

O revolvimento do solo após quatro anos de cultivo em semeadura direta (tratamento b) teve efeito positivo na maioria dos atributos físicos. Na avaliação aos seis meses, a densidade do solo, embora apresente forte tendência à diminuição, não diferiu da original $(\mathrm{P}>0,05)$ (Figura $1 \mathrm{~b})$, e a porosidade total e a macroporosidade mostraram somente tendências de aumento (Figuras 2b e 3b). Essas tendências, embora diminuídas, mantiveram-se com o passar do tempo. 
DENSIDADE DO SOLO, $\mathrm{kg} \mathrm{dm}^{-3}$
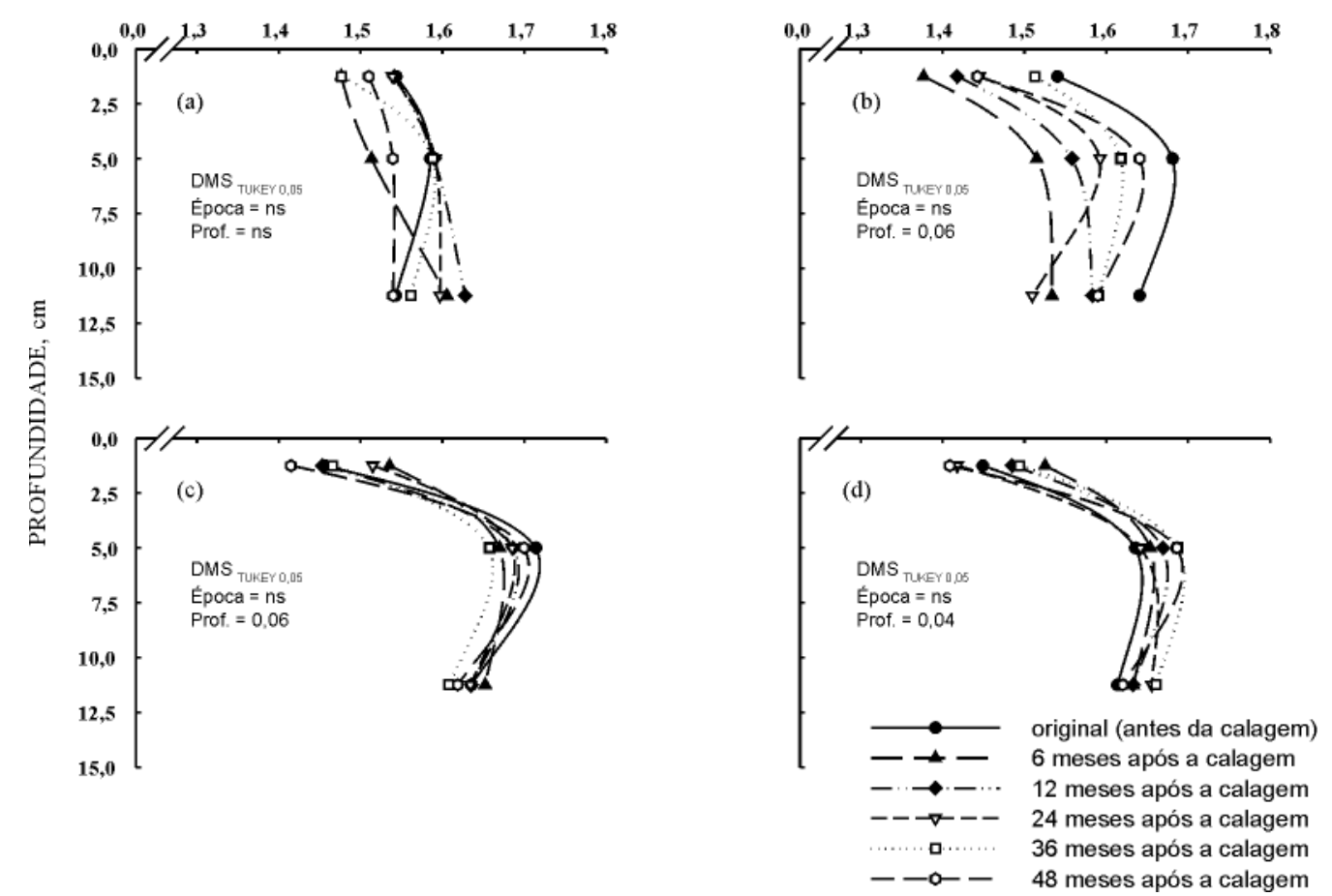

Figura 1. Densidade do solo em diferentes épocas de avaliação, profundidades e sistemas de manejo. (a) convencional durante 12 anos; (b) semeadura direta com revolvimento do solo a cada quatro anos; (c) semeadura direta durante oito anos; (d) semeadura direta durante 12 anos.

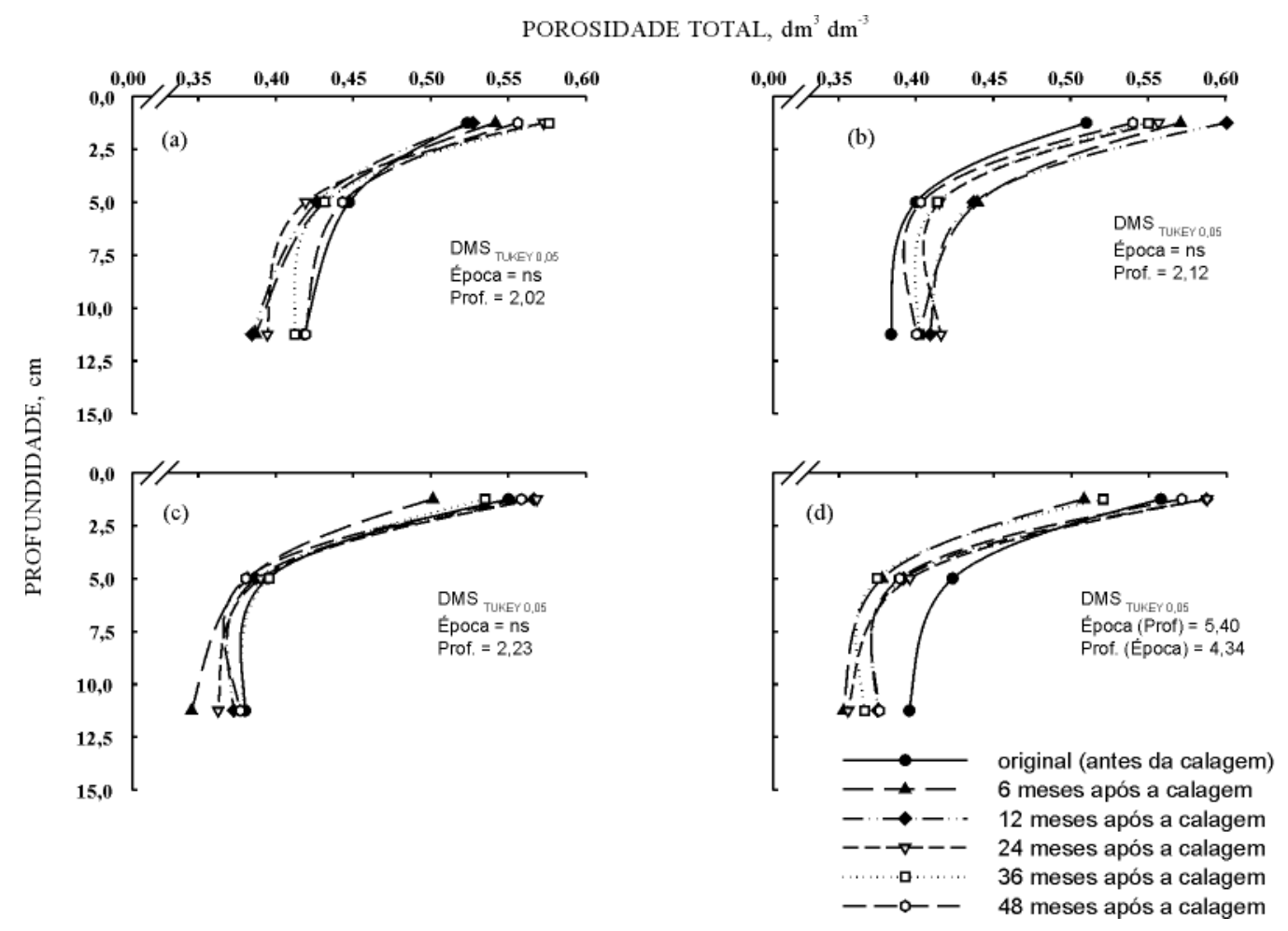

Figura 2. Porosidade total do solo em diferentes épocas de avaliação, profundidades e sistemas de manejo.

(a) convencional durante 12 anos; (b) semeadura direta com revolvimento do solo a cada quatro anos; (c) semeadura direta durante oito anos; (d) semeadura direta durante 12 anos. 


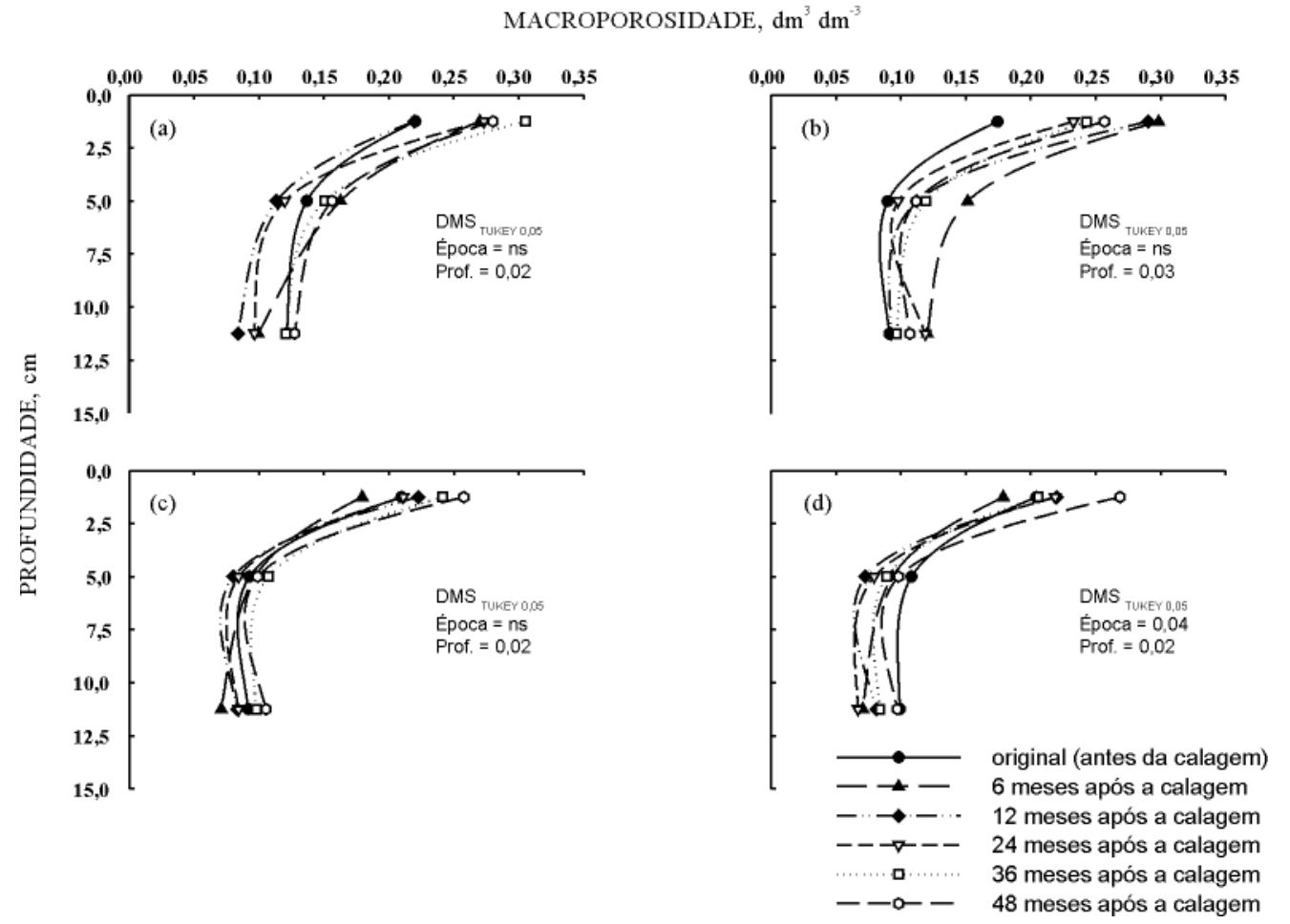

Figura 3. Macroporosidade do solo em diferentes épocas de avaliação, profundidades e sistemas de manejo.

(a) convencional durante 12 anos; (b) semeadura direta com revolvimento do solo a cada quatro anos;

(c) semeadura direta durante oito anos; (d) semeadura direta durante 12 anos.

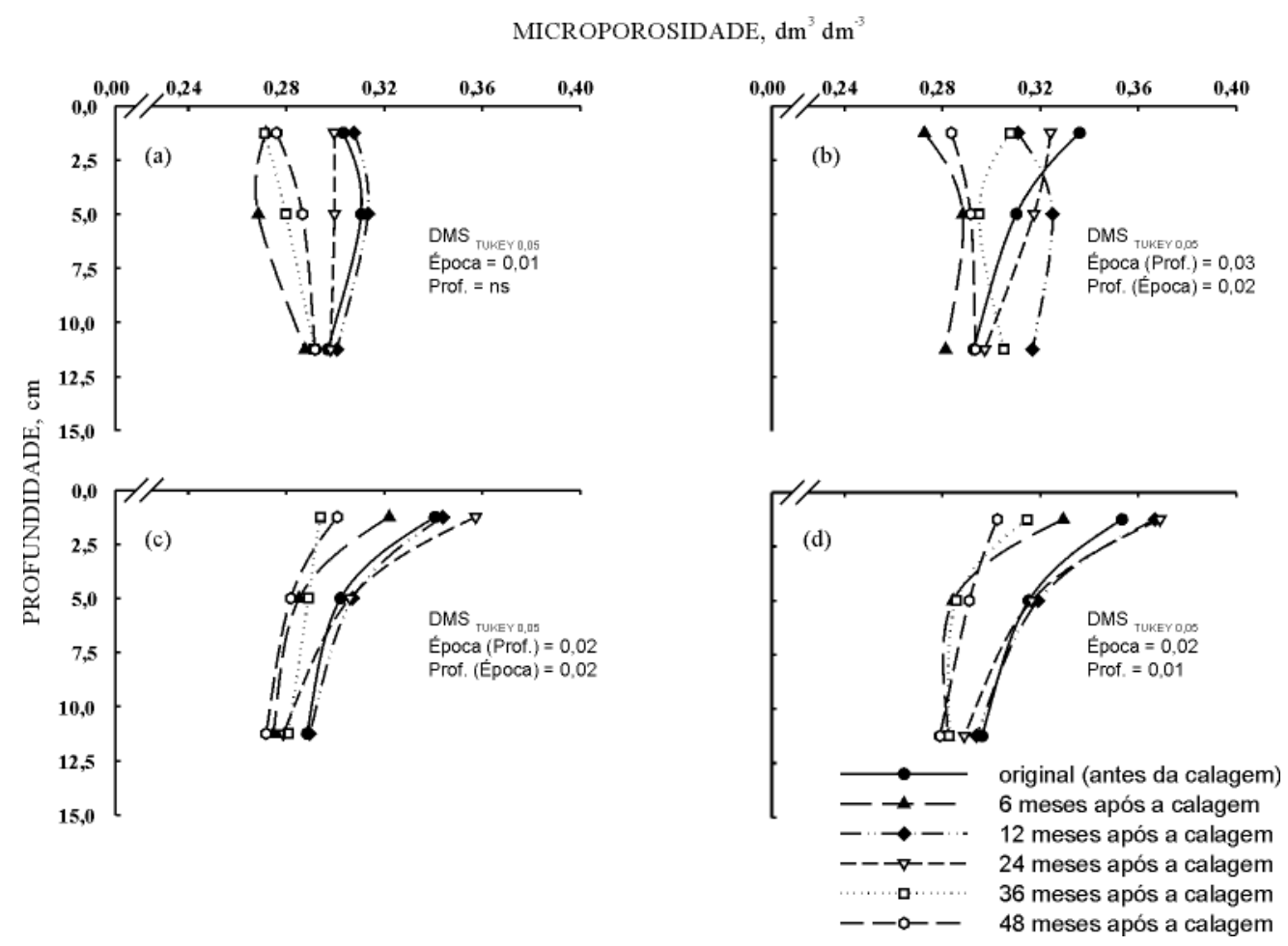

Figura 4. Microporosidade do solo em diferentes épocas de avaliação, profundidades e sistemas de manejo. (a) convencional durante 12 anos; (b) semeadura direta com revolvimento do solo a cada quatro anos; (c) semeadura direta durante oito anos; (d) semeadura direta duante 12 anos. 
Antes do revolvimento do solo com quatro anos de semeadura direta, a densidade média das três profundidades era de $1,62 \mathrm{~kg} \mathrm{dm}^{-3}$, e, após o revolvimento, de $1,47,1,52,1,52,1,57$ e 1,56 $\mathrm{kg} \mathrm{dm}^{-3}$, aos $6,12,24$, 36 e 48 meses, respectivamente (Figura 1b). Embora não tenha ocorrido diferença $(\mathrm{P}>0,05)$, pode-se verificar diminuição na primeira avaliação após o revolvimento do solo, que, com o passar do tempo, retornou à situação inicial.

Nos tratamentos de sistema semeadura direta por 8 e 12 anos, não se esperavam diferenças nos atributos físicos entre as seis avaliações, uma vez que não houve revolvimento do solo. As diferenças existentes $(\mathrm{P}<0,05)$ na porosidade total, macroporosidade e microporosidade, especialmente no sistema semeadura direta com 12 anos e na camada de $0-2,5 \mathrm{~cm}$ (Figuras 2c,d, 3c,d e 4c,d), não eram esperadas.

O preparo convencional do solo, embora apresente tendência de diminuir em relação ao original, não alterou $(\mathrm{P}>0,05)$ o índice de estabilidade de agregados nas diferentes épocas avaliadas (Figura 5a), conforme esperado, mesmo que, na primeira avaliação, os valores possam ser considerados elevados. Para o sistema semeadura direta com revolvimento do solo a cada quatro anos, o índice de estabilidade de agregados foi menor quando o solo foi revolvido (Figura 5b). Decorridos 24 meses do revolvimento, esse índice já mostrou, especialmente nas camadas de 2,5-7,5 e 7,5$15,0 \mathrm{~cm}$, retorno em direção à situação inicial, o que ocorreu totalmente aos 48 meses. Neste tratamento, um maior índice de estabilidade de agregados na condição original (Figura 5b) está relacionado a um maior teor de C (Figura 6b). Com o revolvimento do solo, parte da matéria orgânica que estava na superfície foi incorporada à camada subsuperficial e outra parte foi, provavelmente, mineralizada, explicando, assim, o menor índice de estabilidade de agregados na avaliação de seis meses depois, em relação ao gradiente inicial. A diminuição do teor de $\mathrm{C}$ após o revolvimento, devido à mineralização, justifica, ao menos em parte, os menores índices de estabilidade de agregados na camada superficial do solo nas primeiras épocas avaliadas.

Perdas na qualidade estrutural do solo após uma aração e duas gradagens, em área de semeadura direta por quatro anos, foram também encontradas por Fucks et al. (1994), visto que parte dos agregados maiores e mais estáveis, formados ao longo do tempo, foram reduzidos por meio das operações de preparo do solo.

Como no sistema semeadura direta contínua (8 e 12 anos) não houve revolvimento do solo, não eram esperadas diferenças, no tempo, para o índice de estabilidade de agregados, o que, de maneira geral, aconteceu (Figura 5c,d). Entretanto, na camada de 7,5-15,0 cm do sistema semeadura direta por 8 anos (Figura 5c) houve diferenças, provavelmente, devido a variações naturais do solo. Em conformidade com o índice de estabilidade de agregados, o teor de $\mathrm{C}$

ÍNDICE DE ESTABILIDADE DE AGREGADOS
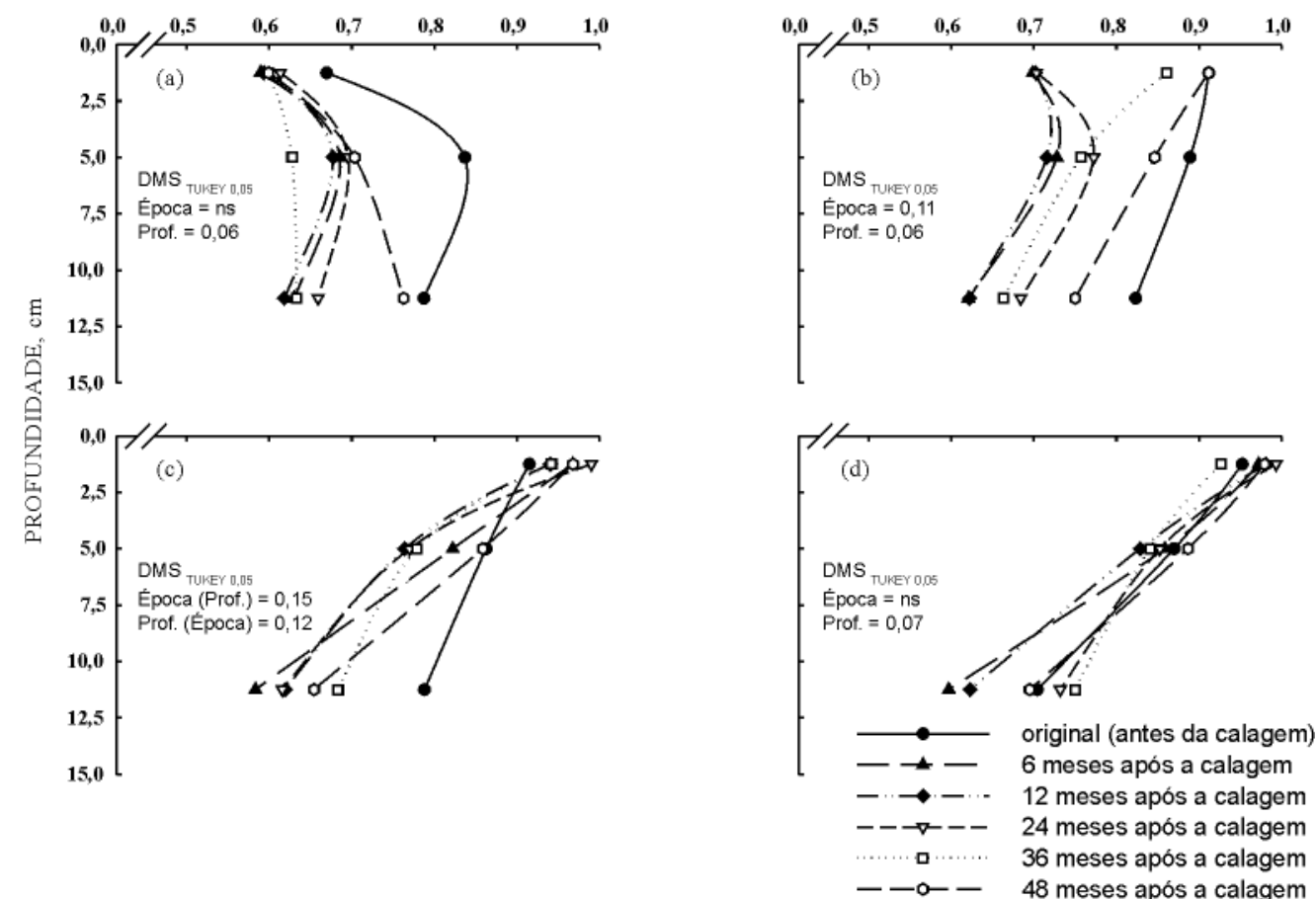

Figura 5. Índice de estabilidade de agregados em diferentes épocas de avaliação, profundidades e sistemas de manejo. (a) convencional durante 12 anos; (b) semeadura direta com revolvimento do solo a cada quatro anos; (c) semeadura direta durante oito anos; (d) semeadura direta durante 12 anos. 


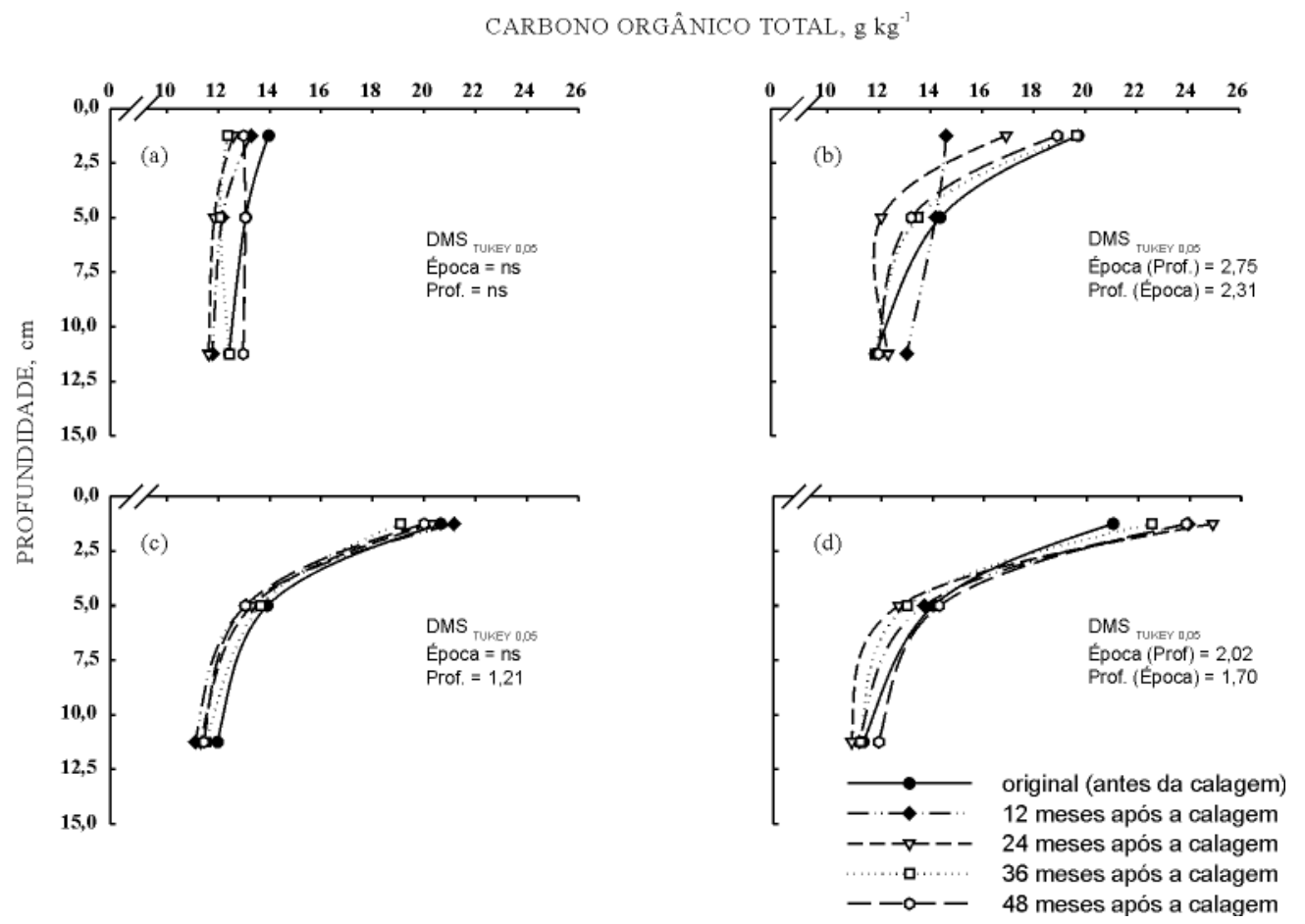

Figura 6. Carbono orgânico total do solo em diferentes épocas de avaliação, profundidades e sistemas de manejo: (a) convencional durante 12 anos; (b) semeadura direta com revolvimento do solo a cada quatro anos; (c) semeadura direta durante oito anos; (d) semeadura direta durante 12 anos.

(Figura 6c,d), de maneira geral, também não mostrou diferenças entre as épocas avaliadas. As diferenças encontradas na camada de $0-2,5 \mathrm{~cm}$ do sistema semeadura direta de 12 anos (Figura 6d) devem-se também, provavelmente, a variações do próprio solo. Mesmo assim, obteve-se alta relação entre o teor de C orgânico e o índice de estabilidade de agregados $\left(\mathrm{r}^{2}=\right.$ 0,86 e $0,91, \mathrm{P}<0,05$, respectivamente para o sistema semeadura direta de 8 e 12 anos). Índices de estabilidade de agregados, com correlações altamente significativas com o C orgânico, foram também observados por Carpenedo \& Mielniczuk (1990) e Castro Filho et al. (1998).

No sistema semeadura direta contínua (8 e 12 anos), a exemplo do teor de C, o índice de estabilidade de agregados apresenta formação de gradiente no perfil do solo, sendo maior na camada superficial, em relação às demais e, também, em relação ao preparo convencional, que apresenta distribuição mais uniforme no perfil do solo, uma vez que este é revolvido anualmente. Com o revolvimento do solo, após quatro anos de semeadura direta, o gradiente desaparece. Além das forças destrutivas da ação mecânica (uma aração e duas gradagens), o solo revolvido fica exposto à desagregação pelo impacto das gotas da chuva, o que, somado à mineralização da matéria orgânica, diminui a estabilidade dos agregados, principalmente na camada superficial. Já no preparo convencional contínuo, o revolvimento anual do solo tende a homogeneizar a camada de solo revolvida. Assim, a tendência é de que os atributos físicos apresentem pouca diferença entre as profundidades e no tempo, resultando em condições bastante parecidas com aquelas do ano anterior.

A tendência de aumento da macroporosidade pelo revolvimento do solo após quatro anos em semeadura direta (Figura 3b), com o passar do tempo, tende a voltar à situação original, em razão do adensamento natural das partículas do solo (Figura 1b). Isso também foi observado para a porosidade total (Figura 2b).

Com a mobilização do solo, há aumento do volume de poros, principalmente dos macroporos, e conseqüente diminuição da densidade (Da Ros et al., 1997). A tendência de aumento na porosidade de aeração, observada pelo revolvimento do solo a cada quatro anos no sistema semeadura direta, é importante, uma vez que os macroporos permitem o rápido fluxo de ar e de água no solo (Culley et al., 1987). A porosidade de aeração destaca-se como um dos atributos mais importantes em relação ao desempenho dos sistemas de manejo do solo sobre a produtividade das culturas. Assim, observa-se, nas camadas subsuperficiais, especialmente nos sistemas semeadura direta de 8 e 12 anos, que a macroporosidade apresenta valores abaixo de $0,10 \mathrm{dm}^{3} \mathrm{dm}^{-3}$ (Figura 3), potencialmente limitantes ao crescimento radicular das plantas (Vomocil \& Flocker, 1961; Grable \& Siemer, 1968). Esse limite depende também do tipo 
de planta e do nível de atividade biológica do solo (Gupta et al., 1989). O fornecimento de oxigênio às raízes depende, no entanto, de vários fatores, incluindo tortuosidade, continuidade e distância entre poros ocupados com ar (Dexter, 1988). Segundo Reinert et al. (1984), solos cultivados no sistema semeadura direta facilitam o fluxo de $\mathrm{O}_{2}$, pela manutenção da continuidade de poros, especialmente de bioporos.

Os resultados do presente trabalho mostram que o eventual revolvimento do solo tem efeitos negativos sobre a estabilidade de agregados, porém o cultivo nos quatro anos seguintes no sistema semeadura direta foi suficiente para o solo voltar ao estado anterior à mobilização. O eventual revolvimento do solo, para incorporação de corretivos ou para descompactá-lo após alguns anos de cultivo em sistema semeadura direta, produz efeitos negativos especialmente nos agregados maiores e mais estáveis, formados ao longo do tempo. Por outro lado, esse revolvimento pode diminuir substancialmente a compactação do solo, aumentar sua macroporosidade e incorporar material orgânico, disponibilizando nutrientes. Revolver o solo no sistema semeadura direta pode ser uma opção importante quando a resistência mecânica à penetração de raízes ou o espaço de aeração atingir valores limitantes para a produtividade das culturas.

\section{CONCLUSÕES}

1. O revolvimento do solo para incorporação do calcário no sistema semeadura direta de quatro anos propiciou condições mais favoráveis de densidade e porosidade do solo, mas diminuiu a estabilidade de agregados.

2. Houve necessidade de um período de quatro anos de cultivo do solo no sistema semeadura direta para o retorno da estabilidade de agregados à condição original.

3. Os atributos físicos do solo apresentaram maior uniformidade no preparo convencional, porém com menor estabilidade de agregados na camada superficial, que foi relacionada ao teor de $\mathrm{C}$ orgânico.

\section{LITERATURA CITADA}

AMARAL, A.S.; ANGHINONI, I.; HINRICHS, R. \& BERTOL, I. Movimentação de partículas de calcário no perfil de um Cambissolo em plantio direto. R. Bras. Ci. Solo, 28:359367, 2004.

BLAKE, G.R. \& HARTGE, K.H. Bulk density. In: KLUTE, A., ed. Methods of soil analysis - physical and mineralogical methods. 2.ed. Madison, American Society of Agronomy, Soil Science Society of America, 1986. p.363375 .
CAIRES, E.F.; BANZATTO, D.A. \& FONSECA, A.F. Calagem na superfície em sistema plantio direto. R. Bras. Ci. Solo, 22:161-169, 2000.

CARPENEDO, V. \& MIELNICZUK, J. Estado de agregação e qualidade de agregados de Latossolos Roxos, submetidos a diferentes sistemas de manejo. R. Bras. Ci. Solo, 14:99$105,1990$.

CASTRO FILHO, C.; MUZILli, O. \& PODANOSCHI, A.L. Estabilidade dos agregados e sua relação com o teor de carbono orgânico num Latossolo Roxo distrófico, em função de sistemas de plantio, rotações de culturas e métodos de preparo das amostras. R. Bras. Ci. Solo, 22:527538, 1998

COMISSÃO DE FERTILIDADE DO SOLO - CFS RS/SC. Recomendações de adubação e de calagem para os estados do Rio Grande do Sul e Santa Catarina. 3.ed. Passo Fundo, Embrapa-CNPT/SBCS - Núcleo Regional Sul, 1995. 223p.

CULLEY, J.L.B.; LARSON, W.E. \& RANDALL, G.W. Physical properties of a typic Haplaquoll under conventional and no-tillage. Soil Sci. Soc. Am. J., 51:1587-1593, 1987.

DA ROS, C.O.; SECCO, D.; FIORIN, J.E.; PETRERE, C.; CADORE, M.A. \& PASA, L. Manejo do solo a partir de campo nativo: efeito sobre a forma e estabilidade da estrutura ao final de cinco anos. R. Bras. Ci. Solo, 1:241$247,1997$.

DANIELSON, R.E. \& SUTHERLAND, P.L. Porosity. In: KLUTE, A., ed. Methods of soil analysis - physical and mineralogical methods. 2.ed. Madison, American Society of Agronomy, 1986. p.443-461.

DEXTER, A.R. Advances in characterization of soil structure. Soil Till. Res., 11:199-238, 1988.

EMPRESA BRASILEIRA DE PESQUISA AGROPECUÁRIA EMBRAPA. Sistema Brasileiro de Classificação de Solos. Rio de Janeiro, 1999. 412p.

FUCKS, L.F.; REINERT, D.J.; CAMPOS, B.C.; BORGES, D.F. \& SCAPINI, C. Degradação da estabilidade estrutural pela aração e gradagem de solo sob plantio direto por quatro anos. In: REUNIÃO BRASILEIRA DE MANEJO E CONSERVAÇÃO DO SOLO E DA ÁGUA, 10., Florianópolis, 1994. Anais. Florianópolis, Sociedade Brasileira de Ciência do Solo, 1994. p.196-197.

GRABLE, A.R. \& SIEMER, E.G. Effects of bulk density, aggregate size, and soil water suction on oxygen difusion, redox potentials, and elongation of corn roots. Soil Sci. Soc. Am. Proc., 32:180-186, 1968.

GUPTA, S.C.; SHARMA, P.P. \& DeFRANCHI, S.A. Compaction effects on soil structure. Adv. Agron., 42:311-338, 1989.

KEMPER, W.D. \& CHEPIL, W.S. Size distribution of aggregates. In: BLAKE, C.A., ed. Methods of soil analysis. Madison, American Society of Agronomy, 1965. p.499510 .

MARCOLAN, A.L. Atributos físicos e químicos de um Argissolo e rendimento de culturas em função do seu revolvimento na reaplicação de calcário no sistema plantio direto. Porto Alegre, Universidade Federal do Rio Grande do Sul, 2002. 76p. (Tese de Mestrado) 
MIELNICZUK, J.; BURLE, M.L.; FERNANDES, S.V.; BAYER, C. \& AMADO, T.J.C. Eficiência da aplicação de calcário em sistemas de culturas e preparos de solo. In: CONGRESSO BRASILEIRO DE CIÊNCIA DO SOLO, 25., Viçosa, MG, 1995. Resumos expandidos. Viçosa, MG, Sociedade Brasileira de Ciência do Solo, 1995. p.1848. 1850 .

OLIVEIRA, E.L. \& PAVAN, M.A. Control of soil acidity in notillage system for soybean production. Soil Till. Res., 38:4757, 1996.

PETRERE, C. \& ANGHINONI, I. Alteração de atributos químicos no perfil do solo pela calagem superficial em campo nativo. R. Bras. Ci. Solo, 25:885-895, 2001.

PÖTTKER, D. \& BEN, J.R. Calagem em solos sob plantio direto e em campos nativos do Rio Grande do Sul. In: NUERNBERG, N.J. ed. Conceitos e fundamentos do sistema plantio direto. Lages, SBCS-Núcleo Regional Sul, 1998. p.77-92.

REINERT, D.J.; MUTTI, L.S.M.; ZAGO, A.; AZOLIN, M.A.D. \& HOFFMANN, C.L. Efeito de diferentes métodos de preparo do solo sobre a estabilidade de agregados em solo Podzólico Vermelho-Amarelo. R. Cent. Ci. Rural., 14:1925, 1984.
RHEINHEIMER, D.S.; SANTOS, E.J.S.; KAMINSKI, J.; BORTOLUZZI, E.C. \& GATIBONI, L.C. Alterações de atributos do solo pela calagem superficial e incorporada a partir de pastagem natural. R. Bras. Ci. Solo, 24:797-805, 2000.

SÁ, J.C.M. Calagem em solos sob plantio direto na região dos Campos Gerais, Centro-Sul do Paraná. In: SÁ, J.M. Curso sobre manejo do solo no sistema plantio direto. Ponta Grossa, Fundação ABC, 1996. p.73-107.

SIQUEIRA, O.F.; SCHERER, E.G.; TASSINARI, G.; ANGHINONI, I.; PATELLA, I.F.; TEDESCO, M.J.; MILAN, P.A. \& ERNANI, P.R. Recomendações de adubação e calagem para os Estados do Rio Grande do Sul e Santa Catarina. Passo Fundo, CNPT-Embrapa, 1987. 100p.

TEDESCO, M.J.; GIANELLO, C.; BISSANI, C.; BOHNEN, H. \& VOLKWEISS, S.J. Análise de solo, plantas e outros materiais. 2.ed. Porto Alegre, Universidade Federal do Rio Grande do Sul, 1995. 174p. (Boletim Técnico, 5)

VOMOCIL, J.A. \& FLOCKER, W.J. Effect of soil compaction on storage and movement of soil air and water. Trans. Am. Soc. Agric. Eng., 4:242-246, 1961. 